\title{
Investigation on Protic lonic Liquids as Physical Solvents for Absorption of NO at Low Pressures
}

\author{
Wentao Zheng,* Guibing Xia, Yi Song, Zhengqing Zhu, Hang Li, Weizhong Shi,* and Dong Fang* \\ Cite This: ACS Omega 2021, 6, 28297-28306 \\ Read Online
}

ACCESS |

Wlll Metrics \& More

Article Recommendations

Supporting Information

ABSTRACT: Nitric oxide (NO) absorption in ionic liquids (ILs) is an interesting issue, but little attention has been focused on the removal of NO at low partial pressures. Herein, a series of protic ionic liquids (PILs) based on polyamines as the cation and hydroxybenzenes as the anion were prepared for capturing lowconcentration NO (0-0.6 bar). Triethylenetetramine phenolate ([TETAH $][\mathrm{PhO}])$ showed an excellent absorption performance, with low viscosity, fast absorption rate, and high absorption capacity. The experimental solubility data were fitted by the Krichevsky-Kasarnovsky $(\mathrm{K}-\mathrm{K})$ equation, and the absorption enthalpy $(\Delta H)$ of $\mathrm{NO}$ in $[\mathrm{TETAH}][\mathrm{PhO}]$ was thus calculated to

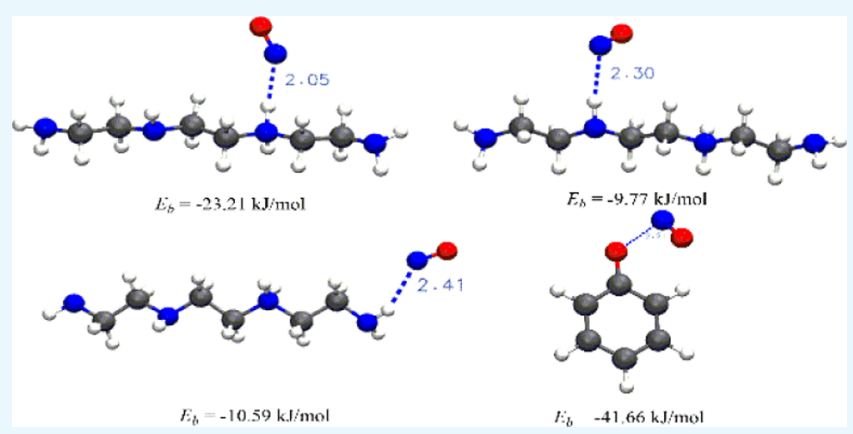
be $-43.60 \mathrm{~kJ} / \mathrm{mol}$. Density functional theory calculations were further performed to better understand the interaction of [TETAH][PhO] with NO on the molecular level, and the results suggest that the weak interaction of NO with the PIL was induced by the presence of $\mathrm{H}$ protons. It is believed that this work may provide a new method for the efficient and reversible absorption of low-concentration NO.

\section{INTRODUCTION}

The emission of nitrogen oxide (NOx) from the combustion of nitrogen-bearing fossil fuels (e.g., coals and oil) is drawing much more attention nowadays as it is one of the main sources to cause photochemical smog and acid rain. ${ }^{1,2}$ It is recorded that more than $90 \%$ of $\mathrm{NOx}$ in the flue gas is nitric oxide (NO). ${ }^{3,4}$ Hence, it is necessary to regulate the NO emissions. Recently, Beijing has performed an ultra-low NOx emission standard for the gas-fired boiler flue gas. ${ }^{5}$ Until now, various denitration technologies have been applied to capture NO in industry, such as selective catalytic reduction (SCR), ${ }^{6}$ selective non-catalytic reduction, ${ }^{7}$ photocatalytic decomposition, ${ }^{8}$ and so forth. Among these denitration methods, SCR is the most successful and widely used technology, ${ }^{9,10}$ whose denitration efficiency could reach up to $90 \%$. However, it still has some drawbacks, such as the high operation temperature, high absorption cost, easy catalyst deactivation and corrosion, and so forth. ${ }^{11,12}$ In addition, the reduction of $\mathrm{NO}$ to $\mathrm{N}_{2}$ is quite wasteful, ${ }^{13,14}$ since NO could be used for synthesizing some nitro chemicals (e.g., nitric acid). Besides, NO could also have a role in the pharmaceutical field as therapeutics for the nervous, cardiovascular, and immune systems. ${ }^{13,15}$ Therefore, developing a new way to efficiently capture NO is of great significance.

Ionic liquids (ILs), low-melting point molten salts entirely composed of ions, ${ }^{16,17}$ have been proposed as a class of stateof-the-art materials due to their outstanding properties, including low volatility, high thermal and chemical stability, wide liquid temperature range, and tunable structures of cations and anions. ${ }^{18-21}$ Consequently, ILs have been investigated systematically and show great potential application in many fields, including electrolysis, catalysis, extraction, and gas absorption. ${ }^{22}$ In particular, the application of ILs for gas absorption is of special interest because of their good affinity to acid gases and avoiding the volatile loss of solvents. ${ }^{23-26}$ During the past few decades, a great number of works have been dedicated to determining the absorption performance of ILs for $\mathrm{CO}_{2}, \mathrm{SO}_{2}$, and $\mathrm{H}_{2} \mathrm{~S}$, and reasonable progress has been achieved in both absorption capacity and transfer performance. $^{27-33}$ However, only a fair amount of effort was focused on the capture of $\mathrm{NO}$ by ILs. ${ }^{34,35}$ Fehrmann group ${ }^{36}$ and Zheng group ${ }^{4}$ successively reported the capture of NO by traditional imidazolium-based ILs through oxidizing $\mathrm{NO}$ to $\mathrm{NO}_{2}$ by $\mathrm{O}_{2}$ at $1 \mathrm{MPa}$. Unfortunately, the oxidation reaction and the dissolution of $\mathrm{NO}_{2}$ in ILs were hard to realize under mild conditions. Since the concentration of NO in the flue gas is only about $0.02-0.2 \mathrm{vol} \%{ }^{4,20}$ some pioneers have designed functional ILs with chemical affinity to NO. In 2016, Wang's group first reported a functional azole-functionalized IL, $\left[\mathrm{P}_{66614}\right][$ Tetz $]$, which could chemically absorb $\mathrm{NO}$ by the $\mathrm{N}$ -

Received: August 17, 2021

Accepted: October 6, 2021

Published: October 15, 2021

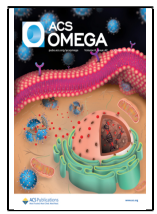


Scheme 1. Chemical Structures of PILs Synthesized in This Work<smiles>NCCNCC[NH2+]CCN</smiles>

[TETAH][PhO]<smiles>COc1ccccc1[O-]</smiles>

[TETAH][GC]

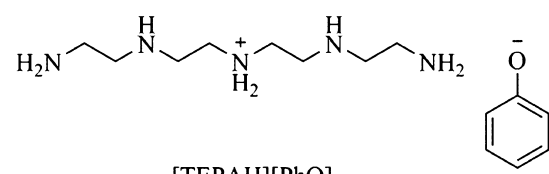<smiles>COc1ccccc1[O-]</smiles>

$[$ TEPAH][GC]

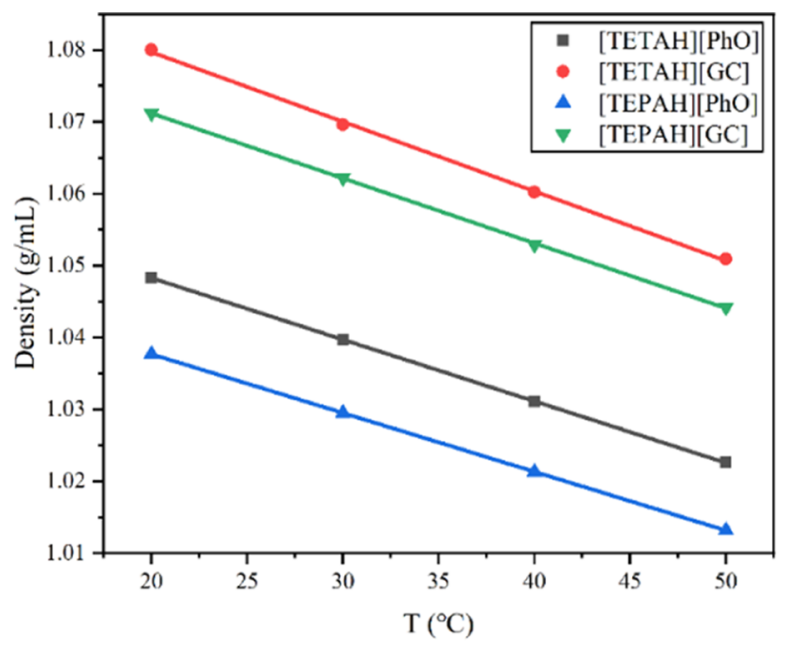

(a)

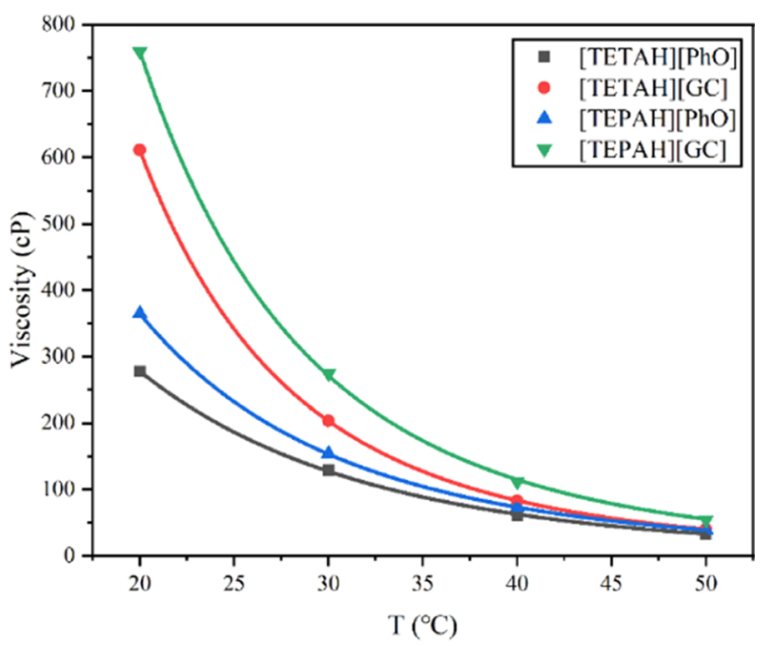

(b)

Figure 1. Density (a) and viscosity (b) of PILs as a function of temperature.

site on the anion to form $-\mathrm{N}(\mathrm{NO}) \mathrm{NOate} .{ }^{34}$ It was shown that the molar ratio of $\mathrm{NO}$ to $\mathrm{IL}$ was as high as $4.52 \mathrm{~mol} \mathrm{NO} / \mathrm{mol}$ IL for pure NO gas at $303.2 \mathrm{~K}$. Later, some ILs containing the $\mathrm{N}$-site were designed and applied for the efficient capture of NO. For example, Greer et al. pointed out that the azole-based IL $\left[\mathrm{P}_{66614}\right][$ Benzim $]$ exhibited relatively high $\mathrm{NO}$ solubility through multiple-site chemical absorption between the $\mathrm{N}$-site and NO. ${ }^{20} \mathrm{Wu}$ et al. designed dual functional ILs containing amine groups in the cation and azole groups in the anion, and the absorption capacity could reach $6.79 \mathrm{~mol} \mathrm{NO} / \mathrm{mol} \mathrm{IL}$ (conditions: $303.2 \mathrm{~K}$ and 1 bar). ${ }^{10}$ In 2021, Wang's group designed a tetrakis(azolyl)borate IL $\left[\mathrm{P}_{66614}\right]\left[\mathrm{B}(\mathrm{Im})_{4}\right]$ to capture $\mathrm{NO}$, exhibiting an ultrahigh absorption capacity of up to $8.13 \mathrm{~mol} \mathrm{NO} / \mathrm{mol} \mathrm{IL} \mathrm{(conditions:} 303.2 \mathrm{~K}$ and $1 \mathrm{bar}$ ). ${ }^{37}$ All these high absorption capacities were achieved by the interaction between the $\mathrm{N}$-site and NO. However, the desorption residue of these ILs was quite high due to a toostrong interaction induced by the $\mathrm{N}$-site, leading to the low working capacity and huge energy input in the desorption process. In view of this situation, Wang et al. proposed a new strategy to design the IL with an $\mathrm{O}$-site to replace the $\mathrm{N}$-site and further tune the interaction between the anion and $\mathrm{NO}$ via basicity. ${ }^{38}$ They designed a series of ILs with carboxylate and sulfonate as the anions for NO capture with the absorption capacity of more than $6 \mathrm{~mol} \mathrm{NO} / \mathrm{mol} \mathrm{IL}$ (conditions: $303.2 \mathrm{~K}$ and 1 bar). Such a high absorption capacity resulted from the chemical interaction between $\mathrm{NO}$ and the $\mathrm{O}$-site on the anion.
These investigations have made some significant advancements and provided vitally important information on $\mathrm{NO}$ absorption. Nevertheless, they only provided NO solubility data at ambient pressure or a specific NO concentration, while the solubility data under different low NO partial pressures were missing. In addition, the two-step synthesis of these ILs was considerably tedious and involves expensive reactants, which severely limited their large-scale applications in industry. Therefore, it is necessary to design functionalized ILs to possess a high NO loading capacity at low partial pressures, with low energy consumption, and a simple synthesis process.

A protic IL (PIL) is synthesized by the equimolar neutralization of a Brønsted acid and a Brønsted base, with the $\mathrm{H}$ proton transferring from the acid to the base to form an anion and a cation..$^{29,30,39,40}$ In comparison with aprotic ionic liquids, a simple one-step synthesis process of PIL is attractive to scientists and industry. In particular, the presence of an $\mathrm{H}$ proton significantly reduces the basicity of the PILs. Hence, the interaction of $\mathrm{NO}$ with a PIL can be weakened so that the energy consumption of the regeneration process will decrease. $^{44}$ In this work, we designed a series of PILs based on polyamines (TETA and TEPA) as the Brønsted base and equimolar hydroxybenzenes (phenol and guaiacol) as the Brønsted acid. The two kinds of hydroxybenzenes used in this work are simple, cheap, and extensive, which have wide applications in industry. In particular, guaiacol is natural and non-toxic, which make it an ideal anion for the PILs. During 
the synthesis process, the $\mathrm{H}$ proton on the hydroxybenzenes transfers to the polyamines, reducing the basicity of the PILs and the volatility of the polyamines. The synthesized PILs were [TETAH $][\mathrm{PhO}],[$ TEPAH $][\mathrm{PhO}], \quad[\mathrm{TETAH}][\mathrm{GC}]$, and $[\mathrm{TEPAH}][\mathrm{GC}]$, and their structures are shown in Scheme 1. They are expected to show excellent absorption performance in both the absorption capacity and desorption energy consumption. On one hand, these PILs possess an $\mathrm{N}$-site on the cations and an $\mathrm{O}$-site on the anions, enabling them to have good affinity to $\mathrm{NO}$; on the other hand, the presence of a $\mathrm{H}$ proton can weaken the interaction between NO and the PILs, so that the energy needed in the desorption process could be reduced. Herein, the absorption of NO in these PILs was systematically investigated, including the effect of the PIL species, temperature, NO partial pressure, and so forth. The experimental results showed that these PILs have a good NO reversible absorption performance, providing a possibility for NO capture in industry.

\section{RESULTS AND DISCUSSION}

2.1. Physical Properties. Densities and viscosities of liquid absorbents are fundamental parameters for a denitrification process. Herein, the densities and viscosities of the synthesized PILs were measured at different temperatures, and the results are shown in Figure 1. Generally speaking, the densities of the four PILs show a negative linear relationship with temperature, while the viscosities decreased nonlinearly with increasing temperature. The densities and viscosities could be fitted with eqs 1 and 2, respectively. ${ }^{44}$

$$
\begin{aligned}
& \rho=a+b T \\
& \eta=\eta_{0} \exp \left(\frac{D}{T-T_{0}}\right)
\end{aligned}
$$

In eqs 1 and 2, $\rho$ and $\eta$ represent the density in $\mathrm{g} / \mathrm{mL}$ and the viscosity in $\mathrm{cP}$ of the PILs, respectively. $a, b, \eta_{0}, D$, and $T_{0}$ are empirical parameters. The fitting results are presented in Table 1.

Table 1. Fitted Empirical Parameters in Eqs 1 and 2

\begin{tabular}{lcccc} 
parameters & $\begin{array}{c}{[\mathrm{TETAH}]} \\
{[\mathrm{PhO}]}\end{array}$ & $\begin{array}{c}{[\mathrm{TEPAH}]} \\
{[\mathrm{PhO}]}\end{array}$ & $\begin{array}{c}{[\mathrm{TETAH}]} \\
{[\mathrm{GC}]}\end{array}$ & $\begin{array}{c}{[\mathrm{TEPAH}]} \\
{[\mathrm{GC}]}\end{array}$ \\
$a$ & 1.07 & 1.05 & 1.10 & 1.09 \\
$b \times 10^{4}$ & -8.57 & -9.67 & -9.67 & -9.03 \\
$\eta_{0}$ & 0.0146 & 0.0089 & 0.0181 & 0.0081 \\
$D$ & 1114 & 1192 & 882 & 1158 \\
$T_{0}$ & -93.0 & -92.3 & -64.6 & -81.2 \\
\hline
\end{tabular}

The densities of the four PILs follow the sequence of $[$ TETAH $][\mathrm{GC}]>[$ TEPAH $][\mathrm{GC}]>[$ TETAH $][\mathrm{PhO}]>$ $[\mathrm{TEPAH}][\mathrm{PhO}]$. It is found that the PILs with $[\mathrm{GC}]$ as the anion have higher densities than those with $[\mathrm{PhO}]$ as the anion. This is reasonable as the density of 2-hydroxyanisole is larger than that of phenol. High viscosity is a common concerned issue for functionalized ILs, as viscous absorbents require more energy to transport and disfavor the gas diffusion in them. ${ }^{31}$ It is found in Figure $1 \mathrm{~b}$ that the viscosities of the four PILs were $277.8-759.8 \mathrm{cP}$ at $20{ }^{\circ} \mathrm{C}$, with the lowest for $[$ TETAH $][\mathrm{PhO}]$ and the highest for $[\mathrm{TEPAH}][\mathrm{GC}]$. Like the density sequence, the PILs with $[\mathrm{PhO}]$ as the anion have much lower viscosities than those with [GC] as the anion. The methoxy group on the [GC] anion should account for its high viscosity as it could form a hydrogen bond with the cations. As for the influence of the cation on the viscosity, the PILs with [TEPAH] as the cation were more viscous than those with the [TETAH] cation. This phenomenon might be attributed to the longer alkyl chain and the extra amine group of [TEPAH]. Even though the viscosities of the four PILs were a bit high at $20{ }^{\circ} \mathrm{C}$, they reduced significantly to $61.0-111.7 \mathrm{cP}$ at $40{ }^{\circ} \mathrm{C}$ and $33.10-53.88 \mathrm{cP}$ at $50{ }^{\circ} \mathrm{C}$. This is a remarkable advantage for these four PILs over other functionalized ILs reported previously.

2.2. Absorption Rate of NO in PILs. Absorption rate is a fundamental parameter for evaluating the absorbents' absorption performance. Figure 2 shows the absorption

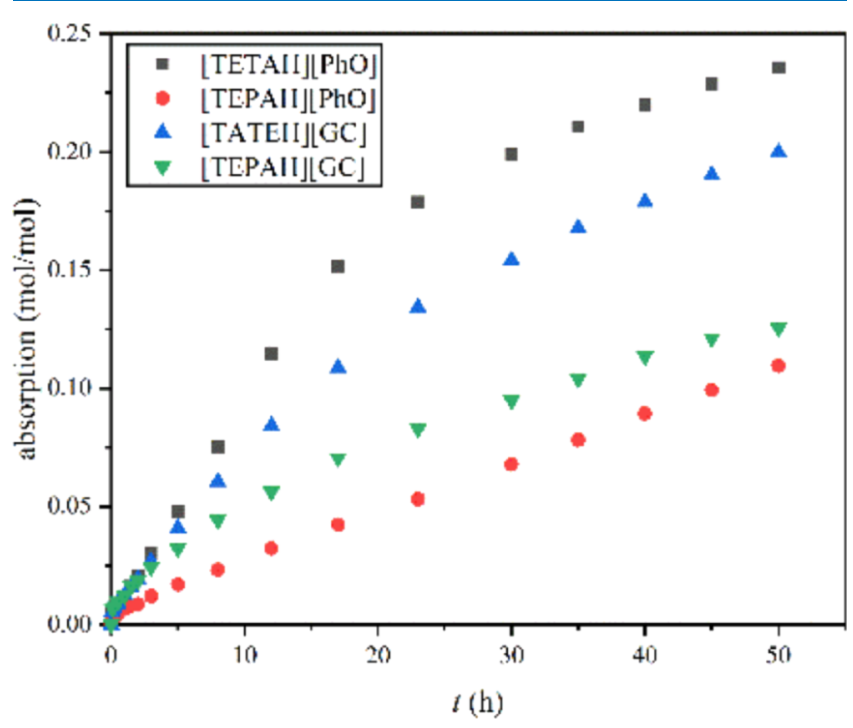

Figure 2. Kinetic absorption of $\mathrm{NO}$ by PILs at $P_{1}=1$ bar and $T=$ $313.2 \mathrm{~K}$.

profiles of NO in the four PILs at $P_{1}=1$ bar and $T=313.2$ $\mathrm{K}$ as a function of time $t$. It was shown that the absorption rate of $\mathrm{NO}$ in the PILs increases steeply in the first stage of absorption $(0-15 \mathrm{~h})$ and then slows down with increasing time. Generally speaking, the absorption rate is mainly dominated by the absorbent's viscosity and concentration. ${ }^{40}$ Both the low viscosity and high concentration can facilitate the absorption rate. Hence, the four PILs' decreasing concentration and increasing viscosities along with absorption might account for the reduction of their absorption rate. In addition, the absorption rate of the four PILs was interestingly found to follow the sequence of $[$ TETHA $][\mathrm{PhO}]>[$ TETAH $][\mathrm{GC}]>$ $[$ TEPAH $][\mathrm{GC}]>[$ TEPAH $][\mathrm{PhO}]$. Except [TEPAH $][\mathrm{PhO}]$, the sequence of $\mathrm{NO}$ absorption rate in the other three PILs is just the opposite of their viscosity order. For example, the viscosities of $[\mathrm{TETHA}][\mathrm{PhO}],[\mathrm{TETAH}][\mathrm{GC}]$, and [TEPAH] [GC] at $313.2 \mathrm{~K}$ were $61.02,82.80$, and 111.70 $\mathrm{cP}$, respectively. This result is reasonable because the low viscosity is beneficial to mass transfer. Although the viscosity of [TEPAH $][\mathrm{PhO}]$ was just $72.76 \mathrm{cP}$ under the same conditions, its absorption rate was the lowest. This phenomenon might be attributed to the alkalinity of the absorbents. As the acidity of the guaiacol was weaker than phenol, the basicity of [GC] (conjugate base) was therefore stronger than $[\mathrm{PhO}]$. As a Lewis acid, NO would be more inclined to interact with those with higher alkalinity. Therefore, the absorption rate of $[\mathrm{TEPAH}][\mathrm{PhO}]$ was lower than those with $[\mathrm{GC}]$ as the anion. 
2.3. Effect of NO Partial Pressure on Absorption by PILs. As the concentration of $\mathrm{NO}$ in the flue gas is relatively low, the absorbent's ability to trap low-concentration $\mathrm{NO}$ is of vital importance to evaluate the absorption performance. Figure 3 shows the solubility of $\mathrm{NO}$ in the four PILs under a

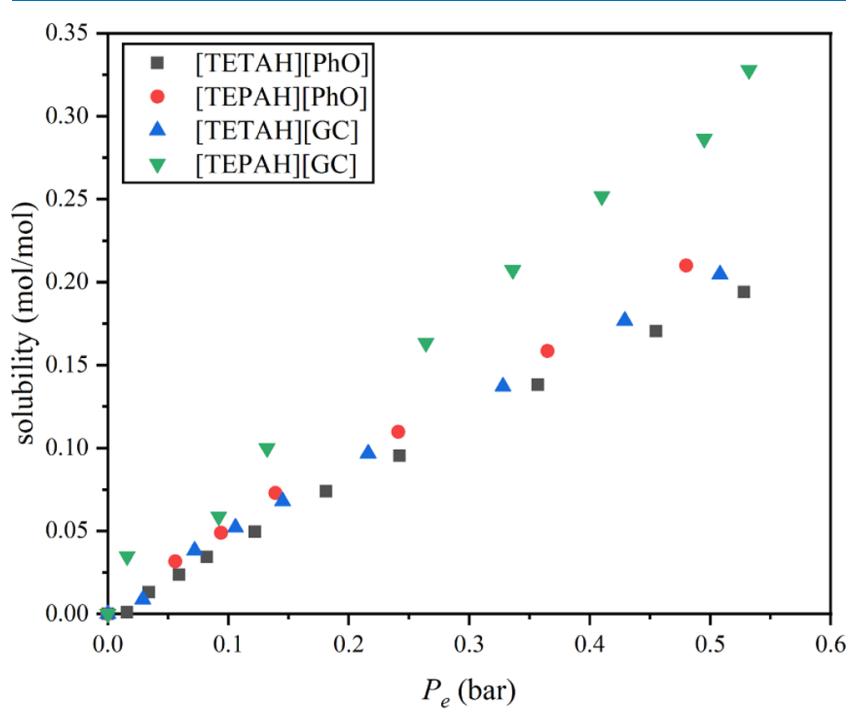

(a)

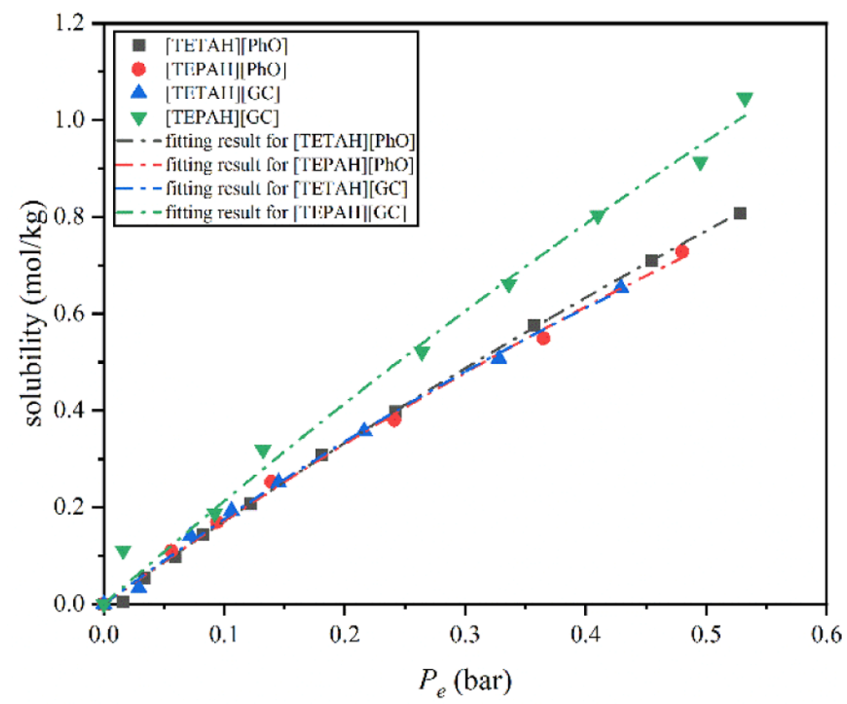

(b)

Figure 3. Effect of NO partial pressure on the relative absorption (a) and absolute absorption (b) by PILs at $313.2 \mathrm{~K}$. (Dotted lines: fitting results by $\mathrm{K}-\mathrm{K}$ equation,)

low partial pressure $(0-0.6$ bar $)$ at $313.2 \mathrm{~K}$. The solubility expressed in units of molar ratio (Figure $3 \mathrm{a}$ ) and absorption in units of molality (Figure 3b) were both introduced in this work to show the relative and absolute NO uptake of the four PILs. It is obvious that the absorption of NO in these four PILs displayed physical behavior, so that the solubility of $\mathrm{NO}$ increased almost linearly with pressure. The same phenomenon was also found in other kinds of PILs reported before. ${ }^{35}$ The cause might reside on the fact that the alkalinity of these PILs was reduced due to the presence of $\mathrm{H}$ protons. As a result, the interaction of NO with PILs was markedly weakened. However, these four PILs still showed comparably good affinity to $\mathrm{NO}$, with the solubilities in the range of 0.035 $\mathrm{mol} / \mathrm{mol}$ (about $0.16 \mathrm{~mol} \mathrm{NO} / \mathrm{kg} \mathrm{IL}$ ) to $0.065 \mathrm{~mol} / \mathrm{mol}$ (about $0.22 \mathrm{~mol} \mathrm{NO} / \mathrm{kg} \mathrm{IL}$ ) at $0.1 \mathrm{bar}$ and $0.182 \mathrm{~mol} / \mathrm{mol}$ (about $0.50 \mathrm{~mol} \mathrm{NO} / \mathrm{kg} \mathrm{IL}$ ) to $0.325 \mathrm{~mol} / \mathrm{mol}$ (about 0.62 $\mathrm{mol} \mathrm{NO} / \mathrm{kg} \mathrm{IL}$ ) at 0.5 bar. Such a large solubility justifies the advantage of these PILs over other physical absorbents on the capture of NO. It could be seen in Figure $3 \mathrm{a}$ that the NO relative solubilities followed the sequence of [TEPAH] [GC] > $[\mathrm{TETAH}][\mathrm{GC}] \approx[\mathrm{TEPAH}][\mathrm{PhO}]>[\mathrm{TETAH}][\mathrm{PhO}]$. It was deduced that the PILs with [TEPAH] as the cation could absorb more NO than those with [TETAH], while the PILs with [GC] as the anion showed a higher absorption efficiency than those with $[\mathrm{PhO}]$. The results could be explained by the alkalinity of the PILs. As for the cation, its alkalinity could be enhanced with the increase of amine groups, while the alkalinity of $[\mathrm{GC}]$ is larger than that of $[\mathrm{PhO}]$ owing to the electron-donating effect of the methoxyl group. Since NO is an acid gas, the PILs with higher alkalinity could therefore be superior to others in solubility. In addition, according to the sequence of solubility, it could also be found that the anion played a more important role in NO solubility than the cation. This could be explained by the fact that the negative $\mathrm{O}$-site on the phenolic anion was much more alkaline than the protonated cation. Correspondingly, the interactions between $\mathrm{NO}$ and the anions were much stronger than those between $\mathrm{NO}$ and the cations.

As for the absolute absorption capacity, it could be seen from Figure $3 \mathrm{~b}$ that [TEPAH] [GC] has the highest absolute solubility, and this is the result of its huge relative absorption capacity, while the remaining PILs showed very close NO uptake to each other, and $[\mathrm{TETAH}][\mathrm{PhO}]$ was even slightly higher than the other two. This was because the molar mass of [TETAH][PhO] was $240.3 \mathrm{~g} / \mathrm{mol}$, being the smallest among them. Though its relative absorption capacity for $\mathrm{NO}$ was a little lower, its absolute uptakes for $\mathrm{NO}$ could be comparable to the other two PILs owing to its small molar mass. In consideration of the viscosity, absorption rate, and absorption capacity, $[\mathrm{TETAH}][\mathrm{PhO}]$ was selected as the representative for the following investigations on temperature.

2.4. Effect of Temperature on NO Absorption by PILs. To investigate the effect of temperature on $\mathrm{NO}$ absorption, the absorption isotherm profiles of [TETAH] $[\mathrm{PhO}]$ at different temperatures are presented in Figure 4. It is obvious that the absorption capacity of NO in the PIL shows a downward trend with the increase of temperature. For example, the solubility of $\mathrm{NO}$ at 0.3 bar decreased by $77 \%$ (from 0.66 to $0.15 \mathrm{~mol} / \mathrm{kg}$ ) when the temperature was increased from 303.2 to $333.2 \mathrm{~K}$. This is reasonable as the gas absorption is an exothermic process. ${ }^{40}$ In addition, it also demonstrated the fact that the NO desorption process had already occurred at $333.2 \mathrm{~K}$. Hence, it is believed that a lower temperature is beneficial for the NO absorption process, while a higher temperature is favorable for the $\mathrm{NO}$ desorption process and the regeneration of the PILs.

2.5. Comparison of PILs Designed in This Work with Other NO Absorbents. To compare the PILs designed in this work with other previously reported absorbents, the absorption capacities of NO in other protic ILs (entries 6 and 7), aprotic ILs (entries 8-10), and traditional amine

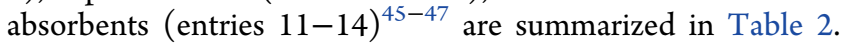
The amine solutions showed extremely high absorption 


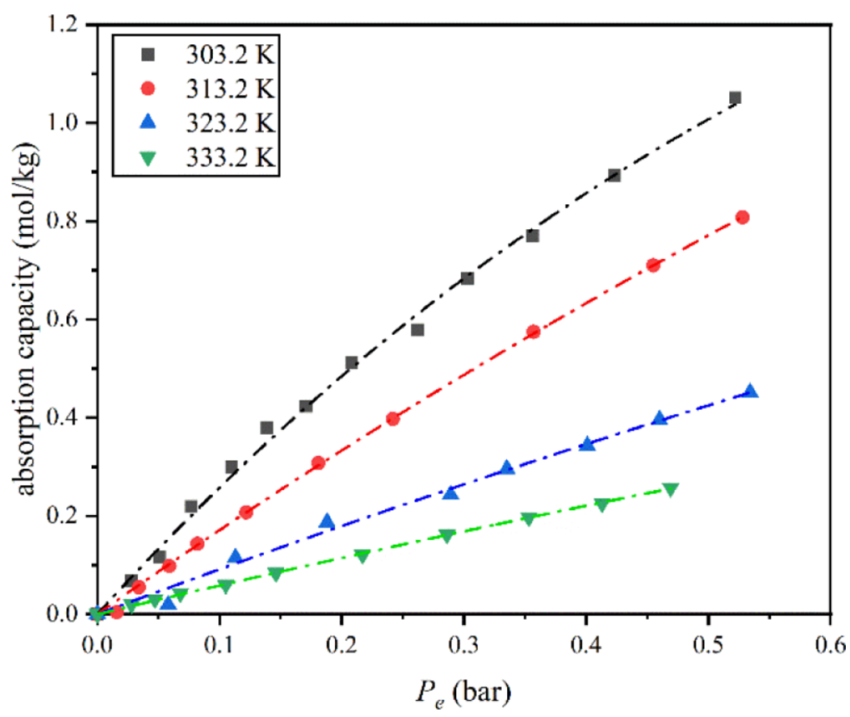

Figure 4. Effect of temperature on NO absorption by PILs. (Dotted lines: fitting results by $\mathrm{K}-\mathrm{K}$ equation.)

uptakes (14-34 mol $\cdot \mathrm{kg}^{-1}$ ). However, their absorption process required the superbases and high NO pressures. Such severe absorption conditions tremendously limited their large-scale application in industry. In comparison with other protic ILs ([TMGH $][\mathrm{PhO}]$ and $[\mathrm{DBUH}][\mathrm{PhO}])$, the PILs designed in this work (entries 1-5) showed much higher absorption capacities, increasing by dozens of times. The results indicate the superiority of these PILs over other kinds of protic ILs. As for the aprotic ILs, they had relatively high NO solubilities even at low NO concentrations. Such high solubilities were achieved by multiple-site absorption, and the viscosities of these system might be largely enhanced during the absorption process, not to mention the fact that they were difficult to desorb NO. In contrast, the absorption capacity of $\mathrm{NO}$ in [TETAH] $[\mathrm{PhO}]$ reduced from 0.78 to $0.18 \mathrm{~mol} \cdot \mathrm{kg}^{-1}$ with the NO pressure decreasing from 0.5 to 0.1 bar. This implies the easy regeneration of $[\mathrm{TETAH}][\mathrm{PhO}]$ with vacuum treatment. As for the IL functionalized with the ferrous ion (entry 10), it might be easily oxidized by oxygen so that its absorption capacity is lost. In view of the above-mentioned conditions, the PILs designed in this work have their own advantages and may be considered as a kind of promising absorbents for the capture of NO.

2.6. Thermodynamic Analysis. As for the modeling of NO absorption in the PILs, since the solubility of NO increased almost linearly with pressure, displaying an apparently physical type of absorption, the classic Krichevsky-Kasarnovsky $(\mathrm{K}-\mathrm{K})$ equation ${ }^{44,48}$ was accurate enough to correlate the solubilities of $\mathrm{NO}$. The $\mathrm{K}-\mathrm{K}$ equation can be written as

$$
\ln \frac{P}{m_{\mathrm{NO}} / m^{\circ}}=\ln H_{\mathrm{m}}+\frac{V^{\infty} P}{R T}
$$

In eq $3, P$ is the pressure of $\mathrm{NO}$ in bar; $m_{\mathrm{NO}}$ is the total solubility of $\mathrm{NO}$ in $\mathrm{mol} / \mathrm{kg}$ in the PILs; $m^{\circ}$ is the standard molality $(1 \mathrm{~mol} / \mathrm{kg}) ; H_{\mathrm{m}}$ is the Henry's law constant in bar; $V^{\infty}$ is the partial molar volume of $\mathrm{NO}$ at infinite dilution; $R$ is the universal gas constant, and $T$ is the experimental temperature. The fitting lines are presented in Figure $3 \mathrm{~b}$, and the fitting data

Table 2. Comparison of NO Absorption by PILs in This Work with Other Absorbents

\begin{tabular}{|c|c|c|c|c|c|c|}
\hline Entry & Absorbents & $\mathrm{T}(\mathrm{K})$ & $\begin{array}{c}\text { NO pressure } \\
\text { (atm) }\end{array}$ & Base & $\begin{array}{c}\text { NO uptakes } \\
(\mathrm{mol} / \mathrm{kg})\end{array}$ & Reference \\
\hline 1 & [TETAH] $[\mathrm{PhO}]$ & 303.2 & 0.5 & No & 1.02 & This work \\
\hline 2 & [TETAH] $[\mathrm{PhO}]$ & 313.2 & 0.5 & No & 0.79 & This work \\
\hline 3 & [TETAH][PhO] & 323.2 & 0.5 & No & 0.42 & This work \\
\hline 4 & {$[\mathrm{TETAH}][\mathrm{PhO}]$} & 313.2 & 0.1 & No & 0.18 & This work \\
\hline 5 & [TEPAH][GC] & 313.2 & 0.5 & No & 0.92 & This work \\
\hline 6 & {$[\mathrm{TMGH}][\mathrm{PhO}]$} & 313.2 & 0.5 & No & 0.06 & 35 \\
\hline 7 & {$[\mathrm{DBUH}][\mathrm{PhO}]$} & 313.2 & 0.5 & No & 0.08 & 35 \\
\hline 8 & {$\left[\mathrm{P}_{66614}\right][$ Tetz $]$} & 303.2 & $10 \%$ & No & 5.91 & 34 \\
\hline 9 & [Ch][L-Pro] & 303.2 & $0.16 \%$ & No & 2.34 & 13 \\
\hline 10 & {$[\mathrm{Bmim}]_{2} \mathrm{FeCl}_{4}$} & 303.2 & $0.4 \%$ & No & 0.68 & 14 \\
\hline 11 & & RT & 3 & $\mathrm{NaOMe}$ & 34 & 45 \\
\hline 12 & & RT & 3.5 & $\mathrm{NaOMe}$ & 17 & 45 \\
\hline 13 & & -78 & 1 & $\mathrm{NaOH}$ & 14 & 46 \\
\hline 14 & & - & 27 & $\mathrm{NaOH}$ & 20 & 47 \\
\hline
\end{tabular}


Table 3. Thermodynamic Parameters of NO Absorption by Dual Functionalized PILs

\begin{tabular}{lcccc}
\multicolumn{1}{c}{ parameters } & {$[\mathrm{TETAH}][\mathrm{PhO}]$} & {$[\mathrm{TEPAH}][\mathrm{PhO}]$} & {$[\mathrm{TETAH}][\mathrm{GC}]$} & {$[\mathrm{TEPAH}][\mathrm{GC}]$} \\
$H_{\mathrm{m}}(\mathrm{bar})$ & $0.57 \pm 0.01$ & $0.56 \pm 0.03$ & $0.52 \pm 0.02$ & $0.46 \pm 0.04$ \\
$V^{\infty}\left(\mathrm{cm}^{3} \cdot \mathrm{mol}^{-1}\right)$ & 6674 & 9711 & 17,045 & 6962 \\
$R^{2}$ & 0.999 & 0.996 & 0.996 & 0.991
\end{tabular}

Table 4. Henry's Constant and Enthalpy Change $\Delta H$ of NO Absorption in [TETAH] $\mathrm{PhO}$

\begin{tabular}{rcccccc}
$T(\mathrm{~K})$ & $H_{\mathrm{m}}(\mathrm{bar})$ & $V \infty\left(\mathrm{cm}^{3} \cdot \mathrm{mol}^{-1}\right)$ & $R^{2}$ & $\Delta H(\mathrm{~kJ} / \mathrm{mol})$ & $\Delta G\left(\mathrm{~kJ} / \mathrm{mol}^{2}\right)$ & $\Delta S\left(\mathrm{~J} \cdot \mathrm{mol}^{-1} \cdot \mathrm{K}^{-1}\right)$ \\
303.2 & $0.37 \pm 0.01$ & 15,456 & 0.997 & -43.60 & 2.51 & -152 \\
313.2 & $0.57 \pm 0.01$ & 6674 & 0.999 & & -0.18 & -144 \\
323.2 & $1.07 \pm 0.08$ & 4851 & 0.991 & & -1.44 & -134 \\
333.2 & $1.68 \pm 0.03$ & 4826 & 0.999 & & -126 \\
\hline
\end{tabular}

of $H_{\mathrm{m}}$ and $V^{\infty}$ are shown in Table 3 . As can be seen, the $\mathrm{K}-\mathrm{K}$ equation can fit the solubilities of $\mathrm{NO}$ in the four PILs accurately, with all the correlation coefficiencies $\left(R^{2}\right)$ larger than 0.99. All the partial molar volumes of $\mathrm{NO}$ at infinite dilution $\left(V^{\infty}\right)$ are positive, indicating that $\mathrm{NO}$ tends to penetrate into the bulky phase of the solvent so that it is thermodynamically stable. The result agrees well with the high solubility of NO in the PILs. As can be seen, the Henry's law constants $\left(H_{\mathrm{m}}\right)$ of $\mathrm{NO}$ in the PILs followed the sequence of $[$ TETAH $][\mathrm{PhO}]>[\mathrm{TEPAH}][\mathrm{PhO}]>[\mathrm{TETAH}][\mathrm{GC}]>$ [TEPAH] $[\mathrm{GC}]$. A larger $H_{\mathrm{m}}$ represented the lower solubility of NO. ${ }^{44}$ Therefore, the correlation result of the $\mathrm{K}-\mathrm{K}$ equation is consistent with experimental data, further implying its high accuracy.

The enthalpy change $\Delta H$ is a useful parameter to evaluate the thermal effect of the absorption process, as well as the energy consumption during the desorption process. ${ }^{26}$ The enthalpy of $\mathrm{NO}$ absorption in [TETAH] $\mathrm{PhO}]$ could be calculated by the van't Hoff equation ${ }^{48}$ (eq 4) based on the Henry's constants $H_{\mathrm{m}}$ of $\mathrm{NO}$ in the IL at different temperatures.

$$
\frac{\partial \ln H_{\mathrm{m}}}{\partial(1 / T)}=\frac{\Delta H}{R}
$$

As can be seen, $\Delta H$ could be calculated from the slopes of the curve $\ln H_{\mathrm{m}}$ versus $1 / T$. Therefore, the values of $H_{\mathrm{m}}$ at different temperatures should be determined in advance. Herein, [TETAH] $[\mathrm{PhO}]$ is taken as an example. The $H_{\mathrm{m}}$ values of $\mathrm{NO}$ absorption in [TETAH] $[\mathrm{PhO}]$ at different temperatures were also obtained by using eq 3 to fit the solubility data at $303.2-333.2 \mathrm{~K}$, and the fitting results are summarized in Table 4 and Figure 4. It is within our expectation that the values of $H_{\mathrm{m}}$ increased with increasing temperature. The larger the $H_{\mathrm{m}}$, the lower the absorption capacity is. As reported in previous part, high temperatures would reduce the NO solubility. Therefore, the $H_{\mathrm{m}}$ value at higher temperatures is larger. Figure 5 shows the dependence of $\ln H_{\mathrm{m}}$ at $303.2,313.2,323.2$, and $333.2 \mathrm{~K}$ for the absorption of $\mathrm{NO}$ in [TETAH][PhO]. It could be seen that there was a high linear fit between $\ln H_{\mathrm{m}}$ and $1 / T . \Delta H$ could thus be obtained from the slope of $\ln H_{\mathrm{m}}$ versus $1 / T$, and the value was calculated to be $-43.60 \mathrm{~kJ} / \mathrm{mol}$. Such a small $\Delta H$ indicated the weak interaction of NO with the PIL. Herein, the weak interaction was further investigated by Fourier transform infrared (FT-IR) spectroscopy (Figures S13-S16 in Supporting Information) and ${ }^{1} \mathrm{H}$ NMR and ${ }^{13} \mathrm{C}$ NMR spectroscopy (Figures S17-S24 in Supporting Information). As can be seen, there was no obvious change after the absorption of $\mathrm{NO}$ for all

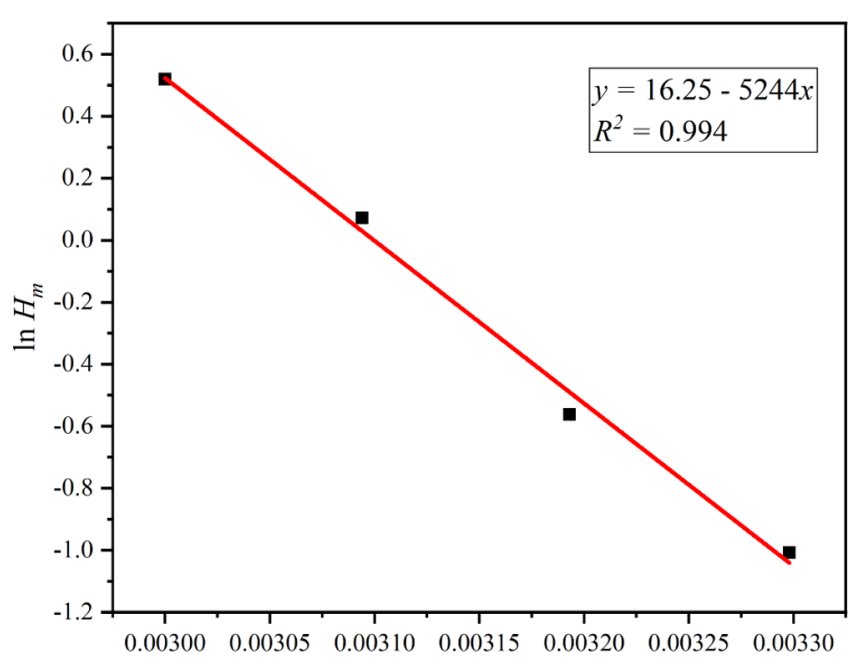

$1 / T$

Figure 5. Calculation of the absorption enthalpy of $\mathrm{NO}$ in [TETAH] $\mathrm{PhO}]$.

the PILs, including no appearance of a new signal and no visible chemical shift. Both the small $\Delta H$ and the spectral results demonstrated that the absorbed NO could be easily desorbed by high-temperature treatment with low energy consumption. ${ }^{40}$

The Gibbs free energy $(\Delta G)$ and entropy change $(\Delta S)$ were also calculated according to eqs 5 and $6,{ }^{33}$ and their values are summarized in Table $4 . \Delta S$ is another important thermodynamic parameter that influences the absorption characteristics. It could be found that the $\Delta S$ values of [TETAH] $[\mathrm{PhO}$ ] were very close $\left(-152\right.$ to $\left.-126 \mathrm{~J} \cdot \mathrm{mol} \cdot \mathrm{K}^{-1}\right)$ at different temperatures $(303.2-333.2 \mathrm{~K})$. In contrast to the small $\Delta H$, the [TETAH][PhO] was accompanied by a large negative $\Delta S$. The result indicates that the NO absorbed in the PIL tended to appear in a more ordered way.

$$
\begin{aligned}
& \Delta G=-R T \ln H_{\mathrm{m}} \\
& \Delta S=(\Delta H-\Delta G) / T
\end{aligned}
$$

To better understand the interaction of [TETAH] $[\mathrm{PhO}]$ with $\mathrm{NO}$ on the molecular level, density functional theory (DFT) calculations were carried out to examine the interaction of the $[\mathrm{TETAH}]$ cation and the $[\mathrm{PhO}]$ anion with $\mathrm{NO}$, and their optimized structures are shown in Figure 6. As for the $[\mathrm{PhO}]$ anion, it has been previously pointed out that the negative $\mathrm{O}$-site on the $[\mathrm{PhO}]$ anion played the primary role in interacting with $\mathrm{NO} ;^{35,38}$ therefore, the contribution of other 
Anion

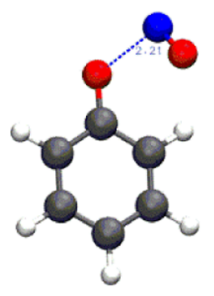

$E_{b}=-41.66 \mathrm{~kJ} / \mathrm{mol}$

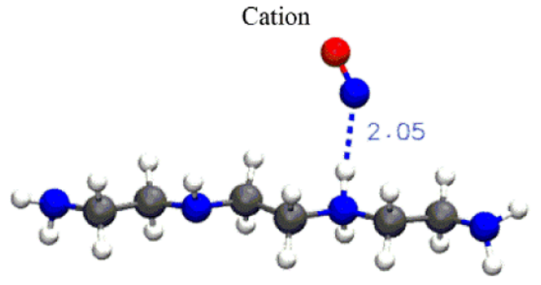

$E_{b}=-23.21 \mathrm{~kJ} / \mathrm{mol}$

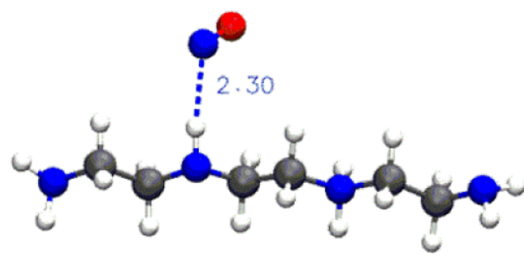

$E_{b}=-9.77 \mathrm{~kJ} / \mathrm{mol}$

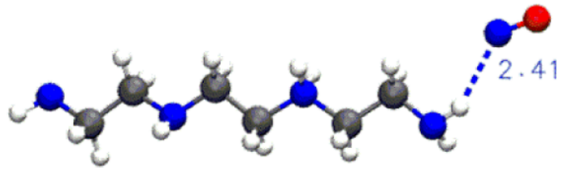

$E_{b}=-10.59 \mathrm{~kJ} / \mathrm{mol}$

Figure 6. Optimized structures of [PhO]-NO and [TETAH]-NO.

groups on the anion was ignored in this work to save computation time. The binding energy of $\mathrm{NO}$ with the [PhO] anion was calculated to be $-41.66 \mathrm{~kJ} / \mathrm{mol}$. As for the cation, most possible modes of interactions were considered (Figure S25 in Supporting Information), and all of them indicated that the $[\mathrm{TETAH}]$ cation interacted with NO through the formation of hydrogen bonds. It could be seen that the $\mathrm{N}$ atom of $\mathrm{NO}$ preferably bound to the $\mathrm{H}$ proton on the protonated secondary amine group $\left(-\mathrm{NH}_{2}{ }^{+}-\right.$group $)$, with the binding energy of $-23.21 \mathrm{~kJ} / \mathrm{mol}$ and the bond length of 2.05 A. Interestingly, the binding energies of $\mathrm{NO}$ with the free secondary amine $(-9.77 \mathrm{~kJ} / \mathrm{mol})$ and the primary amine $(-10.59 \mathrm{~kJ} / \mathrm{mol})$ were much less negative than that of $\mathrm{NO}$ with the $-\mathrm{NH}_{2}{ }^{+}-$group. This phenomenon might be attributed to the fact that the alkalinity of the $\mathrm{N}$-site on the cation was reduced due to the presence of $\mathrm{H}$ proton, so that the interaction strength of $\mathrm{NO}$ with the $\mathrm{N}$-site was weakened. Consequently, the [TETAH] cation interacted with $\mathrm{NO}$ mainly by forming the hydrogen bonds between the $\mathrm{H}$ proton and the $\mathrm{N}$ atom of NO. In addition, the binding energy for interaction between the $[\mathrm{PhO}]$ anion and $\mathrm{NO}(-41.66 \mathrm{~kJ} /$ mol) was much more negative than that for the interaction between the [TETAH] cation and NO $(-23.21 \mathrm{~kJ} / \mathrm{mol})$. This indicates that the interaction between $[\mathrm{PhO}]$ and $\mathrm{NO}$ was stronger than that between [TETAH] and NO, which explained why the solubilities of NO in PILs were mainly determined by the anions.

2.7. Regeneration. The regeneration of an IL is a vitally important criterion to evaluate its potential application. As discussed in the previous part, the interaction of NO with PILs prepared in this work was weak due to the presence of active $\mathrm{H}$ protons. In particular, the enthalpy change $\Delta H$ of $\mathrm{NO}$ absorption in [TETAH] $[\mathrm{PhO}]$ was only about $-43.60 \mathrm{~kJ} /$ mol. Therefore, the absorbed NO could be easily desorbed by high-temperature treatment. Herein, the NO-saturated [TETAH] $[\mathrm{PhO}]$ was heated to $338.2 \mathrm{~K}$ for $60 \mathrm{~min}$. The released NO was removed from the vessel by multiple evacuations. Each evacuation lasts for only $\sim 5 \mathrm{~s}$ in order to avoid the possible evaporation of the PIL. The regenerated PIL was then used for the next NO absorption measurement, and the absorption-desorption cycle was repeated five times. The absorption capacity at 0.3 bar of each cycle is shown in Figure 7. It could be seen that the solubility of NO in the regenerated

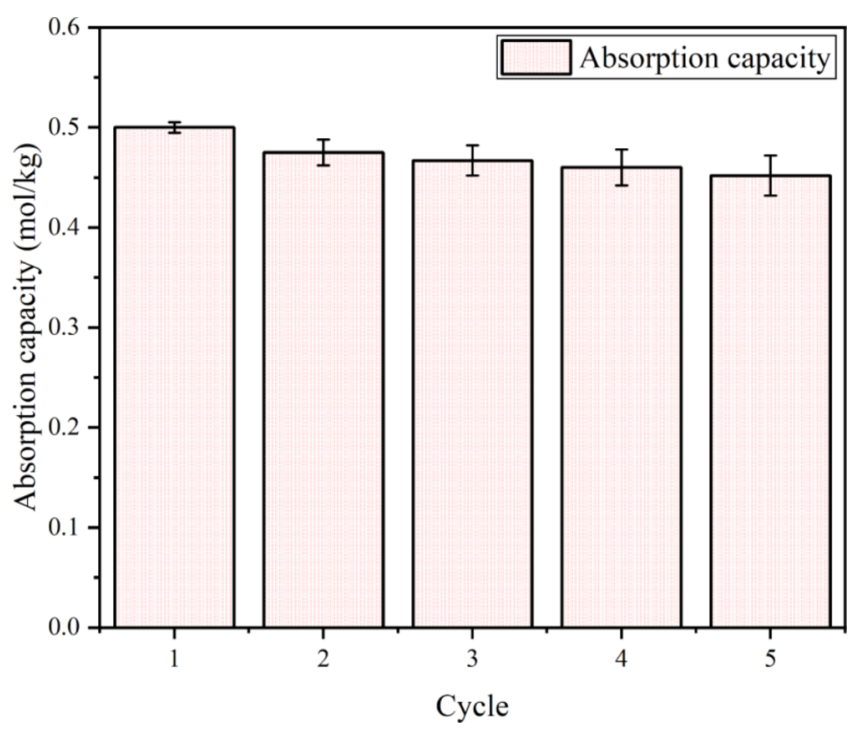

Figure 7. Five absorption-desorption cycles of NO absorption in $[$ TETAH $][\mathrm{PhO}]$.

[TETAH] $[\mathrm{PhO}]$ for each cycle was very close to each other with a loss of $\sim 10 \%$. In fact, most of the capacity loss appears in the first to the second cycle, since high vacuum is not realized. The $[\mathrm{TETAH}][\mathrm{PhO}]$ was reversible with high regeneration efficiency, which was believed to be attributed to the physical absorption behavior of $\mathrm{NO}$ in [TETAH] $[\mathrm{PhO}]$. In addition, the desorption experiment was conducted at 338.2 $\mathrm{K}$, which was much lower than the desorption temperatures of 
other functionalized ILs. ${ }^{34,37,38}$ Such a low desorption temperature significantly reduced the desorption energy consumption. The regenerated experiment revealed that the absorption of $\mathrm{NO}$ by [TETAH] $[\mathrm{PhO}]$ could be reversible with high efficiency and low energy.

\section{CONCLUSIONS}

In summary, a series of PILs based on polyamines as the cations and phenols as the anions were designed and synthesized for the capture of low-concentration NO. Both the absorption kinetics and thermodynamics were investigated systematically. [TETAH][PhO] showed fast absorption rate as a consequence of its low viscosity. As for the thermodynamics, the absorption of NO in these four PILs was found to display physical behavior, as the solubility of $\mathrm{NO}$ increased almost linearly with pressure. The relative absorption capacity of $\mathrm{NO}$ in these PILs follow the sequence of [TEPAH][GC] > $[\mathrm{TETAH}][\mathrm{GC}] \approx[\mathrm{TEPAH}][\mathrm{PhO}]>[\mathrm{TETAH}][\mathrm{PhO}]$. However, the absolute absorption capacity of [TETAH] $\mathrm{PhO}$ was comparable to other PILs owing to its smallest molar mass. Thermodynamic parameters such as Henry's law constant $H_{\mathrm{m}}$, partial molar volumes at infinite dilution $V^{\infty}$, and absorption enthalpies $\Delta H$ were obtained by correlating the experimental $\mathrm{NO}$ solubility data with the $\mathrm{K}-\mathrm{K}$ equation. It was revealed that the interaction of $\mathrm{NO}$ with $[\mathrm{TETAH}][\mathrm{PhO}]$ was weakened due to the presence of $\mathrm{H}$ protons. Consequently, the energy consumption during the desorption process was reduced. The results obtained in this work, together with the low cost and facile synthesis of PILs, make [TETAH][PhO] a promising candidate for capturing low-concentration NO.

\section{EXPERIMENTAL SECTION}

4.1. Materials. NO (99.9 v \%) was purchased from Yancheng City Guangyuan Gas Co. Ltd., Yancheng, China. Triethylenetetramine (95 wt \%, CAS number: 112-24-3), tetraethylenepentamine (95 wt \%, CAS number: 112-57-2), phenol (99 wt \%, CAS number: 108-95-2), and guaiacol (99 wt $\%$, CAS number: 90-05-1) were purchased from Tansoole. All the chemicals were used directly without further purification.

4.2. Preparation and Characterization of PILs. All PILs used in this work were synthesized following a similar route: the ethanolic solutions of polyamines were directly neutralized by stoichiometric phenols to produce the corresponding PILs. Most of ethanol was removed by the rotary evaporator and then the crude PILs were dried under vacuum at $353.2 \mathrm{~K}$ for $24 \mathrm{~h}$ to remove the residual solvent. Their ${ }^{1} \mathrm{H}$ NMR and ${ }^{13} \mathrm{C}$ NMR spectra were collected on a Bruker AVANCE II 400 $\mathrm{MHz}$ UltraShield Plus using $\mathrm{CD}_{3} \mathrm{Cl}$ as the solvent and TMS as the internal standard. The NMR spectra and data are shown in Figures S1-S8 (Supporting Information). TGA was performed on a Netzsch STA 449 C instrument to determine the decomposition temperature. The operation temperature was from room temperature to $573.2 \mathrm{~K}$ with a $10 \mathrm{~K} / \mathrm{min}$ heating rate under a $\mathrm{N}_{2}$ atmosphere during the whole testing process. The decomposition temperature $\left(T_{\mathrm{d}}\right)$ denotes the thermal onset of decomposition at $10 \%$ total mass loss. The TGA results (Figures S9-S12) showed that the decomposition temperature of all these PILs was higher than $403.2 \mathrm{~K}$, implying that they had good stability under the experimental conditions. The densities of these PILs were collected on an Anton Paar DMA 5000 densitometer with an uncertainty of 0.001. The viscosities were determined on a Brookfield LVDV-
II + Pro viscometer with an uncertainty of $\pm 1 \%$ in relation to the full scale.

4.3. Absorption of $\mathrm{NO}$ in PILs. The apparatus for measuring $\mathrm{NO}$ solubilities in the prepared PILs is identical to that reported in our previous work. ${ }^{35,39}$ The whole device is composed of two stainless-steel chambers, whose volumes are $171.0572 \mathrm{~mL}\left(V_{1}\right)$ and $62.9952 \mathrm{~mL}\left(V_{2}\right)$, respectively. The bigger chamber known as the gas reservoir is used to isolate NO before it comes in contact with the PIL in the smaller chamber, while the smaller chamber, called the equilibrium cell, is equipped with a magnetic stirrer. The temperatures (T's) of these two chambers are controlled by a water bath with an uncertainty of $\pm 0.1 \mathrm{~K}$. The pressures of the two chambers are monitored by two pressure transducers (Wide Plus Precision Instruments Co., Ltd.; accuracy: $\pm 0.2 \%$ of the full scale; scale: $0-0.6 \mathrm{MPa})$. The pressure transducers are connected to a Numeric Instrument (WP-D821-200-1212-N$2 \mathrm{P})$ to record the pressure changes online. In a typical run, a known mass $(w)$ of PIL sample was put into the equilibrium cell and then the air in the two chambers was evacuated to be less than 0.010 bar. The residual pressure in the equilibrium cell, resulting from the vapor pressure of the PILs, was recorded to be $P_{0}$. Afterward, NO from its gas cylinder was introduced into the gas reservoir to a pressure of $P_{1}$. The needle valve between the two chambers was then turned on to let part of $\mathrm{NO}$ be fed into the equilibrium cell. The pressure of the gas reservoir was recorded as $P_{1}^{\prime}$, while the pressure of the equilibrium cell decreased gradually during the absorption process until the reaction equilibrium was reached, and the equilibrium pressure was recorded as $P_{2}$. The NO partial pressure in the equilibrium cell was thus denoted to be $P_{\mathrm{e}}=P_{2}$ - $P_{0}$. The NO uptake under pressure $P_{e}, n\left(P_{e}\right)$, could be obtained by the following eq 7

$$
\begin{aligned}
n\left(P_{e}\right)= & \rho_{\mathrm{g}}\left(P_{1}, T\right) V_{1}-\rho_{\mathrm{g}}\left(P_{1}^{\prime}, T\right) V_{1}-\rho_{\mathrm{g}}\left(P_{e}, T\right) \\
& \left(V_{2}-w / \rho_{\mathrm{PIL}}\right)
\end{aligned}
$$

where $\rho_{\mathrm{g}}\left(P_{i}, T\right)$ is the density of $\mathrm{NO}$ in $\mathrm{mol} / \mathrm{mL}$ at pressure $P_{i}$ $(i=1, e)$ and $T$ and $\rho_{\text {PIL }}$ is the density of the PIL sample in $\mathrm{g} /$ $\mathrm{mL}$ at $T$. Continuous measurement of $\mathrm{NO}$ solubility data at elevated pressure was accomplished by introducing more $\mathrm{NO}$ into the equilibrium cell to reach new absorption equilibrium. After the experiments, the NO residue in the two chambers should be fed into an off-gas absorber $(\mathrm{NaOH}$ aqueous solution) to keep NO from leaking into the atmosphere. Duplicate experiments were performed for every PIL system to ensure the accuracy of NO solubility values. The averaged relative deviation of the measured solubility data was well within $\pm 1 \%$.

4.4. Kinetic Measurement of NO Absorption. Kinetic measurements were performed on the same apparatus as that used for solubility determination. The experimental procedure was also similar, except that the initial pressure of the gas reservoir $\left(P_{1}\right)$ was set to $\sim 1$ bar, and the needle valve between the two chambers remained open during the whole reaction process. The pressure decay was recorded as a function of time $(t)$, and the NO uptake at time $t$ was also calculated by eq 7 .

4.5. Theoretical Calculations. A cluster model was used to mimic the systems. First-principles calculations were carried out using DFT with the generalized gradient approximation of Perdew-Burke-Ernzerhof ${ }^{41}$ implemented in the all-electron FHI-aims code. ${ }^{42}$ Long-range van der Waals interactions were corrected via the Tkatchenko-Scheffler scheme. ${ }^{43}$ FHI-aims 
employs atom-centered numeric basis functions. The tight basis sets and numerical settings were employed. The SCF convergence criteria of charge density, total energy, and force were set to $10^{-4}, 10^{-5}$, and $10^{-4}$, respectively. All structures were fully relaxed until the forces on each atom were below $0.02 \mathrm{eV} / \AA$. The binding energies of $\mathrm{NO}$ and the cation (or anion) have been studied systematically via DFT. The binding energies were calculated by subtracting the total energies of a single cation (or anion) and NO from that of the cation (or anion)-NO complex.

\section{ASSOCIATED CONTENT}

\section{SI Supporting Information}

The Supporting Information is available free of charge at https://pubs.acs.org/doi/10.1021/acsomega.1c04445.

Characterization $\left({ }^{1} \mathrm{H}\right.$ NMR and ${ }^{13} \mathrm{C}$ NMR spectra and TG curves) of the PILs, FT-IR and NMR spectra of PILs before and after absorption of NO, and DFT calculations for different modes of interactions between $\mathrm{NO}$ and the [TETAH] cation (ZIP)

\section{AUTHOR INFORMATION}

\section{Corresponding Authors}

Wentao Zheng - School of Chemistry and Environmental Engineering, Yancheng Teachers University, Yancheng, Jiangsu 224007, China; (1) orcid.org/0000-0003-28747782; Email: wentaozheng1990@163.com

Weizhong Shi - School of Chemistry and Environmental Engineering, Yancheng Teachers University, Yancheng, Jiangsu 224007, China; Email: swznh@163.com

Dong Fang - School of Chemistry and Environmental Engineering, Yancheng Teachers University, Yancheng, Jiangsu 224007, China; (1) orcid.org/0000-0002-91477802; Email: fangd@yctu.edu.cn

\section{Authors}

Guibing Xia - School of Chemistry and Environmental Engineering, Yancheng Teachers University, Yancheng, Jiangsu 224007, China

Yi Song - School of Chemistry and Environmental Engineering, Yancheng Teachers University, Yancheng, Jiangsu 224007, China

Zhengqing Zhu - School of Chemistry and Environmental Engineering, Yancheng Teachers University, Yancheng, Jiangsu 224007, China

Hang Li - School of Chemistry and Environmental Engineering, Yancheng Teachers University, Yancheng, Jiangsu 224007, China

Complete contact information is available at: https://pubs.acs.org/10.1021/acsomega.1c04445

\section{Notes}

The authors declare no competing financial interest.

\section{ACKNOWLEDGMENTS}

This work was supported by the Jiangsu Province Emergency Management Science and Technology Project (YJGL-TG2020-10).

\section{REFERENCES}

(1) Chang, S. G.; Liu, D. K. Removal of nitrogen and sulphur oxides from waste gas using a phosphorus/alkali emulsion. Nature 1990, 343, $151-153$.

(2) Volz, A.; Kley, D. Evaluation of the Montsouris series of ozone measurements made in the nineteenth century. Nature 1988, 332, 240-242.

(3) Deshwal, B. R.; Jin, D. S.; Lee, S. H.; Moon, S. H.; Jung, J. H.; Lee, $\mathrm{H}$. K. Removal of NO from flue gas by aqueous chlorine-dioxide scrubbing solution in a lab-scale bubbling reactor. J. Hazard. Mater. 2008, 150, 649-655.

(4) Li, X.; Zhang, L.; Li, L.; Hu, Y.; Liu, J.; Xu, Y.; Luo, C.; Zheng, C. NO removal from flue gas using conventional imidazolium-based ionic liquids at high pressures. Energy Fuels 2018, 32, 6039-6048.

(5) Wu, Y.; Luo, C.; Wu, W.; Su, Q. Denitration of the gas-fired boiler flue gas based on chemical-looping combustion. Chem. Eng. J. 2019, 361, 41-49.

(6) Jirát, J.; Štěpánek, F.; Marek, M.; Kubíček, M. Comparison of design and operation strategies for temperature control during selective catalytic reduction of NOx. Chem. Eng. Technol. 2001, 24, $35-40$.

(7) Kasuya, F.; Glarborg, P.; Johnsson, J. E.; Dam-Johansen, K. The thermal DeNOx process: influence of partial pressures and temperature. Chem. Eng. Sci. 1995, 50, 1455-1466.

(8) Duan, Y.; Zhang, M.; Wang, L.; Wang, F.; Yang, L.; Li, X.; Wang, C. Plasmonic $\mathrm{Ag}-\mathrm{TiO}_{2}-\mathrm{x}$ nanocomposites for the photocatalytic removal of NO under visible light with high selectivity: the role of oxygen vacancies. Appl. Catal., B 2017, 204, 67-77.

(9) Gao, X.; Jiang, Y.; Zhong, Y.; Luo, Z.; Cen, K. The activity and characterization of $\mathrm{CeO}_{2}-\mathrm{TiO}_{2}$ catalysts prepared by the sol-gel method for selective catalytic reduction of $\mathrm{NO}$ with $\mathrm{NH}_{3}$. J. Hazard. Mater. 2010, 174, 734-739.

(10) Sun, Y.; Ren, S.; Hou, Y.; Zhang, K.; Wu, W. Highly efficient absorption of $\mathrm{NO}$ by dual functional ionic liquids with low viscosity. Ind. Eng. Chem. Res. 2019, 58, 13313-13320.

(11) Djerad, S.; Crocoll, M.; Kureti, S.; Tifouti, L.; Weisweiler, W. Effect of oxygen concentration on the NOx reduction with ammonia over $\mathrm{V}_{2} \mathrm{O}_{5}-\mathrm{WO}_{3} / \mathrm{TiO}_{2}$ catalyst. Catal. Today 2006, 113, 208-214.

(12) Fang, P.; Cen, C.; Tang, Z.; Zhong, P.; Chen, D.; Chen, Z. Simultaneous removal of $\mathrm{SO}_{2}$ and $\mathrm{NOx}$ by wet scrubbing using urea solution. Chem. Eng. J. 2011, 168, 52-59.

(13) Sun, Y.; Ren, S.; Hou, Y.; Zhang, K.; Zhang, Q.; Wu, W. Highly reversible and efficient absorption of low-concentration NO by amino-acid-based ionic liquids. ACS Sustainable Chem. Eng. 2020, 8, $3283-3290$

(14) Sun, Y.; Ren, S.; Hou, Y.; Zhang, K.; Wu, W. Absorption of nitric oxide in simulated flue gas by a metallic functional ionic liquid. Fuel Process. Technol. 2018, 178, 7-12.

(15) Sun, Y.; Gao, M.; Ren, S.; Zhang, Q.; Hou, Y.; Wu, W. Highly efficient absorption of NO by amine-based functional deep eutectic solvents. Energy Fuels 2019, 34, 690-697.

(16) Brennecke, J. F.; Maginn, E. J. Ionic liquids: innovative fluids for chemical processing. AIChE J. 2001, 47, 2384-2389.

(17) Earle, M. J.; Seddon, K. R. Ionic liquids. Green solvents for the future. Pure Appl. Chem. 2000, 72, 1391-1398.

(18) Zhang, S.; Sun, N.; He, X.; Lu, X.; Zhang, X. Physical properties of ionic liquids: database and evaluation. J. Phys. Chem. Ref. Data 2006, 35, 1475-1517.

(19) Dzyuba, S. V.; Bartsch, R. A. Recent advances in applications of room-temperature ionic liquid/supercritical $\mathrm{CO}_{2}$ systems. Angew. Chem., Int. Ed. Engl. 2003, 42, 148-150.

(20) Greer, A. J.; Taylor, S. F. R.; Daly, H.; Quesne, M.; Catlow, C. R. A.; Jacquemin, J.; Hardacre, C. Investigating the effect of NO on the capture of $\mathrm{CO}_{2}$ using superbase ionic liquids for flue gas applications. ACS Sustainable Chem. Eng. 2019, 7, 3567-3574.

(21) Ma, Y.; Zhang, J.; Huang, K.; Jiang, L. Highly efficient and selective separation of ammonia by deep eutectic solvents through cooperative acid-base and strong hydrogen-bond interaction. J. Mol. Liq. 2021, 337, 116463. 
(22) Wang, C.; Luo, H.; Li, H.; Zhu, X.; Yu, B.; Dai, S. Tuning the physicochemical properties of diverse phenolic ionic liquids for equimolar $\mathrm{CO}_{2}$ capture by the substituent on the anion. Chem.-Eur. J. 2012, 18, 2153-2160.

(23) Cao, Y.; Zhang, J.; Ma, Y.; Wu, W.; Huang, K.; Jiang, L. Designing low-viscosity deep eutectic solvents with multiple weakacidic groups for ammonia separation. ACS Sustainable Chem. Eng. 2021, 9, 7352-7360.

(24) Li, P.; Wang, X.; Zhao, T.; Yang, C.; Wang, X.; Liu, F. Deep eutectic solvents formed by EmimCl plus lactams effective $\mathrm{SO}_{2}$ capture and conversion into sulphur via DESs-mediated Claus process. Chem. Eng. J. 2021, 422, 130033.

(25) Wang, C.; Luo, H.; Jiang, D.-e.; Li, H.; Dai, S. Carbon dioxide capture by superbase-derived protic ionic liquids. Angew. Chem., Int. Ed. Engl. 2010, 49, 5978-5981.

(26) Wang, C.; Luo, X.; Luo, H.; Jiang, D.-e.; Li, H.; Dai, S. Tuning the basicity of ionic liquids for equimolar $\mathrm{CO}_{2}$ capture. Angew. Chem., Int. Ed. Engl. 2011, 50, 4918-4922.

(27) Long, G.; Yang, C.; Yang, X.; Zhao, T.; Liu, F.; Cao, J. Bisazolebased deep eutectic solvents for efficient $\mathrm{SO}_{2}$ absorption and conversion without any additives. ACS Sustainable Chem. Eng. 2020, $8,2608-2613$

(28) Long, G.; Yang, C.; Yang, X.; Zhao, T.; Xu, M. Deep eutectic solvents consisting of 1-ethyl-3-methylimidazolium chloride and glycerol derivatives for highly efficient and reversible $\mathrm{SO}_{2}$ capture. J. Mol. Liq. 2020, 302, 112538.

(29) Wei, L.; Guo, R.; Tang, Y.; Zhu, J.; Liu, M.; Chen, J.; Xu, Y. Properties of aqueous amine based protic ionic liquids and its application for $\mathrm{CO}_{2}$ quick capture. Sep. Purif. Technol. 2020, 239, 116531.

(30) Zheng, W.-T.; Zhang, F.; Wu, Y.-T.; Hu, X.-B. Concentrated aqueous solutions of protic ionic liquids as effective $\mathrm{CO}_{2}$ absorbents with high absorption capacities. J. Mol. Liq. 2017, 243, 169-177.

(31) Huang, K.; Zhang, J.-Y.; Hu, X.-B.; Wu, Y.-T. Absorption of $\mathrm{H}_{2} \mathrm{~S}$ and $\mathrm{CO}_{2}$ in aqueous solutions of tertiary-amine functionalized protic ionic liquids. Energy Fuels 2017, 31, 14060-14069.

(32) Huang, K.; Cai, D.-N.; Chen, Y.-L.; Wu, Y.-T.; Hu, X.-B.; Zhang, Z.-B. Thermodynamic validation of 1-alkyl-3-methylimidazolium carboxylates as task-specific ionic liquids for $\mathrm{H}_{2} \mathrm{~S}$ absorption. AIChE J. 2013, 59, 2227-2235.

(33) Wang, Y.; Zheng, C.; Wang, Y.; Chen, H.; Xu, Y. Thermodynamic validation of double bond comprised ionic liquids for $\mathrm{CO}_{2}$ capture. J. Environ. Chem. Eng. 2019, 7, 102774.

(34) Chen, K.; Shi, G.; Zhou, X.; Li, H.; Wang, C. Highly efficient nitric oxide capture by azole-based ionic liquids through multiple-site absorption. Angew. Chem., Int. Ed. Engl. 2016, 55, 14364-14368.

(35) Zheng, W.; Xu, G.; Zhu, Y.; Zhou, L.; Wu, X.; Shi, W. Investigation of phenolic ionic liquids as efficient nitric oxide absorbents. J. Mol. Liq. 2021, 338, 116559.

(36) Kunov-Kruse, A. J.; Thomassen, P. L.; Riisager, A.; Mossin, S.; Fehrmann, R. Absorption and oxidation of nitrogen oxide in ionic liquids. Chem.-Eur. J. 2016, 22, 11745-11755.

(37) Zhai, R.; He, X.; Mei, K.; Chen, K.; Cao, N.; Lin, W.; Li, H.; Wang, C. Ultrahigh nitric oxide capture by tetrakis(azolyl)borate ionic liquid through multiple-sites uniform interaction. ACS Sustainable Chem. Eng. 2021, 9, 3357-3362.

(38) Cao, N.; Gan, L.; Xiao, Q.; Lv, X.; Lin, W.; Li, H.; Wang, C. Highly efficient and reversible nitric oxide capture by functionalized ionic liquids through multiple-site absorption. ACS Sustainable Chem. Eng. 2020, 8, 2990-2995.

(39) Zheng, W.; Wu, D.; Feng, X.; Hu, J.; Zhang, F.; Wu, Y.-T.; Hu, $\mathrm{X}$.-B. Low viscous protic ionic liquids functionalized with multiple lewis base for highly efficient capture of $\mathrm{H}_{2}$ S. J. Mol. Liq. 2018, 263, 209-217.

(40) Zheng, W.-T.; Huang, K.; Wu, Y.-T.; Hu, X.-B. Protic ionic liquid as excellent shuttle of MDEA for fast capture of $\mathrm{CO}_{2}$. AIChE J. 2018, 64, 209-219.

(41) Perdew, J. P.; Burke, K.; Ernzerhof, M. Generalized gradient approximation made simple. Phys. Rev. Lett. 1998, 77, 3865-3868.
(42) Blum, V.; Gehrke, R.; Hanke, F.; Havu, P.; Havu, V.; Ren, X.; Reuter, K.; Scheffler, M. Ab initio molecular simulations with numeric atom-centered orbitals. Comput. Phys. Commun. 2009, 180, 21752196.

(43) Tkatchenko, A.; Scheffler, M. Accurate molecular van der waals interactions from ground-state electron density and free-atom reference data. Phys. Rev. Lett. 2009, 102, 073005.

(44) Huang, K.; Zhang, X.-M.; Hu, X.-B.; Wu, Y.-T. Hydrophobic protic ionic liquids tethered with tertiary amine group for highly efficient and selective absorption of $\mathrm{H}_{2} \mathrm{~S}$ from $\mathrm{CO}_{2}$. AIChE J. 2016, 62, 4480-4490.

(45) Holland, R. J.; Klose, J. R.; Deschamps, J. R.; Cao, Z.; Keefer, L. K.; Saavedra, J. E. Direct reaction of amides with nitric oxide to form diazeniumdiolates. J. Org. Chem. 2014, 79, 9389-9393.

(46) Drago, R. S.; Paul, F. E. The reaction of nitrogen(II) oxide with diethylamine. J. Am. Chem. Soc. 1960, 82, 96-98.

(47) Drago, R. S.; Karstetter, B. R. The reaction of nitrogen(II) oxide with various primary and secondary amines. J. Am. Chem. Soc. 1961, 83, 1819-1822.

(48) Huang, K.; Peng, H.-L. Solubilities of carbon dioxide in 1-ethyl3-methylimidazolium thiocyanate, 1-ethyl-3-methylimidazolium dicyanamide, and 1-ethyl-3-methylimidazolium tricyanomethanide at (298.2 to 373.2) K and (0 to 300.0) kPa. J. Chem. Eng. Data 2017, 62, $4108-4116$ 